\title{
As agências de propaganda, o golpe e a ditadura militar brasileira
}

Advertising agencies, the coup and Brazil's military dictatorship

\section{David Antonio Castro Netto}

É doutor em História pelo Programa de Pós-Graduação em História da Universidade Federal do Paraná. Pesquisa história do Brasil República, com ênfase no período da ditadura militar e nas suas relações com o campo da comunicação e da propaganda.

Submetido em 14 de Junho de 2019 Aceito em 10 de Agosto de 2019

\section{RESUMO}

O objetivo deste texto é discutir qual o papel das agências de propaganda durante uma fase da ditadura militar brasileira, 1964-1968. Primeiro, qual seu papel no período anterior ao golpe (1963 - 1964); segundo, como foi sua atuação na produção de discursos que, de alguma maneira, dessem sustentação à atuação do governo. A partir da análise de algumas campanhas e da posição das instituições de classe, procuramos demonstrar que os profissionais da propaganda, as agências e as campanhas já se mostravam alinhados à ditadura militar, antes mesmo da criação da agência oficial em 1968.

Pallavras-chave: Propaganda; Ditadura Militar; Agências de Propaganda.

\section{ABSTRACT}

The purpose of this paper is to discuss the role of advertising agencies during a phase of the Brazilian military dictatorship, 1964-1968. First, what role did they play in the precoup period (1963-1964) and, second, how they produced discourses that supported the government's actions. From the analysis of some campaigns and the position of the class institutions, we tried to demonstrate that the propaganda professionals, the agencies and the campaigns were already aligned with the military dictatorship, even before the creation of the official agency in 1968.

Keywords: Advertising; Military Dictatorship; Advertising Agencies. 


\section{RESUMEN}

El objetivo de este texto es discutir cuál es el papel de las agencias de propagandas durante una fase de la dictadura militar brasileña, 1964-1968. Primero, cuál es su papel en el período anterior al golpe (1963-1964); segundo, cómo fue su actuación en la producción de discursos que, de alguna manera, dieran soporte a la actuación del gobierno. A partir del análisis de algunas campañas y de la posición de las instituciones de clase, procuramos demostrar que los profesionales de la propaganda, las agencias y las campañas ya se mostraban alineados a la dictadura militar, antes incluso de la creación de la agencia oficial en 1968.

Pallabras-clave: Propaganda, Dictadura Militar, Agencias de Publicidad

\section{Introdução}

Passados mais de 50 anos do golpe militar de 1964, um conjunto robusto de pesquisas conseguiu avaliar de que maneira o contexto social brasileiro degenerou a ponto de a saída golpista ter sido viabilizada, não apenas pelas Forças Armadas, mas também por um conjunto amplo e heterogêneo de forças políticas.

O campo da comunicação também fazia parte deste complexo jogo de forças que, à sua maneira, agiu e reagiu ao conturbado período que vai da renúncia de Jânio Quadros ao golpe militar iniciado em 31 de março e finalizado em 01 de abril de 1964.

São muitos e sólidos os estudos que procuram dimensionar o papel de alguns meios de comunicação, especialmente a atuação da imprensa escrita na construção da imagem "esquerdista", "ditatorial", "golpista" ou "antidemocrática". Autores como Silva (2014) até avançam na expressão "golpe-midiático-civil-militar", para reforçar o papel importante dos meios de comunicação na campanha devastadora contra João Goulart, sobretudo a partir do jornal "Tribuna da Imprensa”. Outros campos também são/foram dignos de pesquisas e análises profundas, como o cinema (ASSIS, 2001) e mesmo a atuação da própria Associação Brasileira de Imprensa (ROLLEMBERG E QUADRAT, 2010). 
Por outro lado, também é notório o papel da comunicação na defesa de João Goulart, a partir da "Campanha da Legalidade", organizada por Leonel Brizola, que contou com apoio e a construção de uma cadeia de rádios para tentar enfrentar as informações produzidas pelo campo alinhado à fração golpista da direita e extrema direita brasileiras.

Como é possível apreender, existe uma discussão, tanto no campo da comunicação, quanto fora dele, a respeito daquilo que podemos chamar de "disputa comunicacional" para garantir uma ação legitimada do espectro vencedor. A decisão autoritária já havia sido clamada pelos jornais de grande circulação, como o Globo e Jornal do Brasil, o que é mais um elemento que demonstra a importância que a comunicação tinha naquele cenário.

Contudo, existe um campo ainda pouco explorado, ao menos no que diz respeito à forma como contribuiu para a construção de legitimidade antes e depois do golpe militar de 1964: o campo das agências de propaganda, seus profissionais e instituições de classe. Este será o objetivo deste texto: examinar de que maneira as agências de propaganda e suas instituições contribuíram na campanha de desestabilização do governo João Goulart e durante o período de 1964-1968, antes da criação da agência oficial - a Assessoria Especial de Relações Públicas (AERP) -, produzindo discursos que se alinhavam às propostas da ditadura.

Para cumprir tais objetivos, utilizaremos, basicamente, um conjunto de materiais recolhidos no periódico Propaganda, não apenas por ser o mais antigo, mas, também, por sua recepção no meio publicitário e circulação. Ali encontramos não apenas as campanhas institucionais das agências, como também a posição das instituições que representavam parte significativa do mercado publicitário brasileiro.

\section{A ditadura militar e a propaganda brasileira: do apoio ao golpe à legitimação da} ditadura

A relação entre as agências e a ditadura militar brasileira começou a ser construída a partir da aproximação entre os golpistas e uma de suas principais 
instituições de classe, a Associação Brasileira de Agências de Publicidade ${ }^{1}$ (Abap). No imediato pós-golpe, um grupo de militares chefiados pelo Gal. Moacyr Gaia e o coronel Araken de Oliveira solicitou à Abap a criação de uma campanha publicitária cujas metas eram "desarmar os espíritos" e "serenar os ânimos" naquele momento de incerteza.

De acordo com Cadena (2001), o resultado dessa aproximação foi a criação do Serviço de Difusão Democrática (SDD), cujas incumbências se aproximavam às de um órgão de relações públicas, a partir da produção de boletins diários. Ainda que o trabalho do SDD tenha sido efêmero, representou a primeira aproximação entre ditadura e agências de propaganda.

Outra instituição de classe a se manifestar foi a Associação Paulista de Propaganda (APP). A APP patrocinou, junto à agência J. W. Thompson, um anúncio intitulado "À Beira do Abismo". 0 anúncio ressaltava o "alívio" da APP após a derrubada do governo João Goulart e projetava novas possibilidades para o Brasil. A revista Propaganda abriu espaço para a circulação do anúncio na edição número 98, maio de 1964:

\footnotetext{
1 Em reunião realizada em 23 de fevereiro de 1949 entre os proprietários das 11 maiores agências do Brasil, discutiu-se a ideia da criação do órgão. A ABAP nascia em 1ํ de agosto de 1949, com sede no Rio de Janeiro, e teve como primeiro presidente Aldo Xavier da Silva. Os objetivos da instituição eram defender o negócio da propaganda e regulamentar o setor. A ABAP esteve presente em todas as grandes decisões da história da propaganda brasileira, como regulamentação das comissões, a organização dos primeiros congressos de propaganda e a criação do Conar.
} 


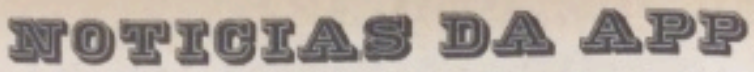

Em fave dos acontedimentioe do mes so abret aitimo,

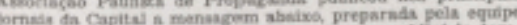

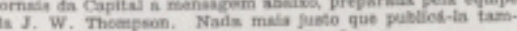

A beira do abismo

À beira do abismo... para ai construir uma das grandes nap̧èes do mundo: quinta em territbrio, oitava em pooulaçalo, d6eima em produto nacional bruto o ampliar-se em petroleo, asco, energia elétrica, celuloso, num ritmo de vida que bestimulo e certeza.

A beira do abismo.... para ai erguer, em dois dectnices, a maior naçâ industrial dos trópicos, o parque manufatureiro que é tratores e turbinas, caminhōes.

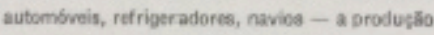
de um nivel de vida mether para todos.

A beina do abismo.... para ai edificar duas das dez maiores édadea do globo... para aí eriar a maior naplo latina e catblica de nossos tampos - a mais expressiva cultura moderna do continente.

A beira do abismo ... porque dessas alturas, onde plantamos nossa bandeira, se desortina melhor o panorama do Futuro, 60 abismo se transforma em brancuras de cdificicas, virasas produtivas, montanhas de cimento, por onde trilharemos novos caminhos, encontrando semore. come ath́ hoje, come tantas vitzes no passado, a perta que conduz à seguranca, aso progresso, à paz!

Associaçåo Paulista de Propaganda

Fonte 1: Revista Propaganda, maio, 1964, s/p.

Embora soasse enigmático, o anúncio ia ao encontro das outras manifestações em favor da ação dos golpistas. 0 destaque vai para a última estrofe que apostava no futuro glorioso, tendo em vista a ultrapassagem do "momento chave", representado pelo governo Goulart. Essa perspectiva otimista ainda encontrava espaço para se manifestar à medida que a sociedade se sentia ator principal dos novos rumos que o Brasil trilharia. 
O editorial da revista ressalta o caráter "necessário" da intervenção militar na política brasileira. Numa mistura de lamento pela ausência de lideranças mais atuantes no setor da propaganda, preocupação com o "projeto estatizante" de João Goulart e comemoração pela saída encontrada:

\begin{abstract}
Antes da Revolução recente, havia preocupação nos meios publicitários. Não sem motivos, receava-se pela estatização (?) da atividade. Com todo o corolário fácil de prever. A coleção de nossos números editados desde abril de 1963, testemunha a nossa própria preocupação. Principalmente pela tranquilidade com que as associações de classe, líderes da profissão, deixam correr os acontecimentos. Só quando principiou a faltar o ar é que uma ou outra janela foi aberta, para o esclarecimento e a definição da independência, da ética, da sintonia da publicidade com o momento e os problemas do país².
\end{abstract}

O corolário de tais aproximações deu-se com a criação do Conselho Nacional de Propaganda (CNP), em 02 de junho de 1964, em assembleia realizada na sede da APP. De acordo com Cadena (2001, p.157), "a revolução amadurece a ideia da criação dentro da classe de um órgão que elabore campanhas institucionais para esclarecer a verdadeira função da propaganda".

O CNP foi formado por anunciantes, agências de propaganda e veículos de divulgação, e seus objetivos iam além da defesa da propaganda. Entre o rol de suas prerrogativas estava "a realização, sem fins lucrativos, de campanhas de caráter cívico, social e filantrópico"3.

No editorial de maio de 1964, a revista salientava o papel que o CNP deveria exercer, sobretudo devido à sua "preocupação de esclarecer autoridades e público"4 sobre os importantes benefícios que traria para a defesa do setor contra as tentativas de controle dos eventuais governos. O CNP patrocinou diversas campanhas "apolíticas" e de cunho cívico. É provável que seu principal trabalho tenha sido a "Campanha Nacional pela Livre Iniciativa", veiculada durante os anos 1979 - 1989.

As campanhas do CNP podem demonstrar muito pouco de apolítico e muito de ideológico. Destacamos um anúncio veiculado na revista Veja, em 16/04/1969:

\footnotetext{
2 Revista Propaganda, no 98, maio 1964, p. 11.

3 Revista Propaganda, no 99, junho 1964, s/p.

${ }^{4}$ Revista Propaganda, no 98, junho 1964, p. 11.
} 
Figura 2: Anúncio Conselho Nacional de Propaganda:

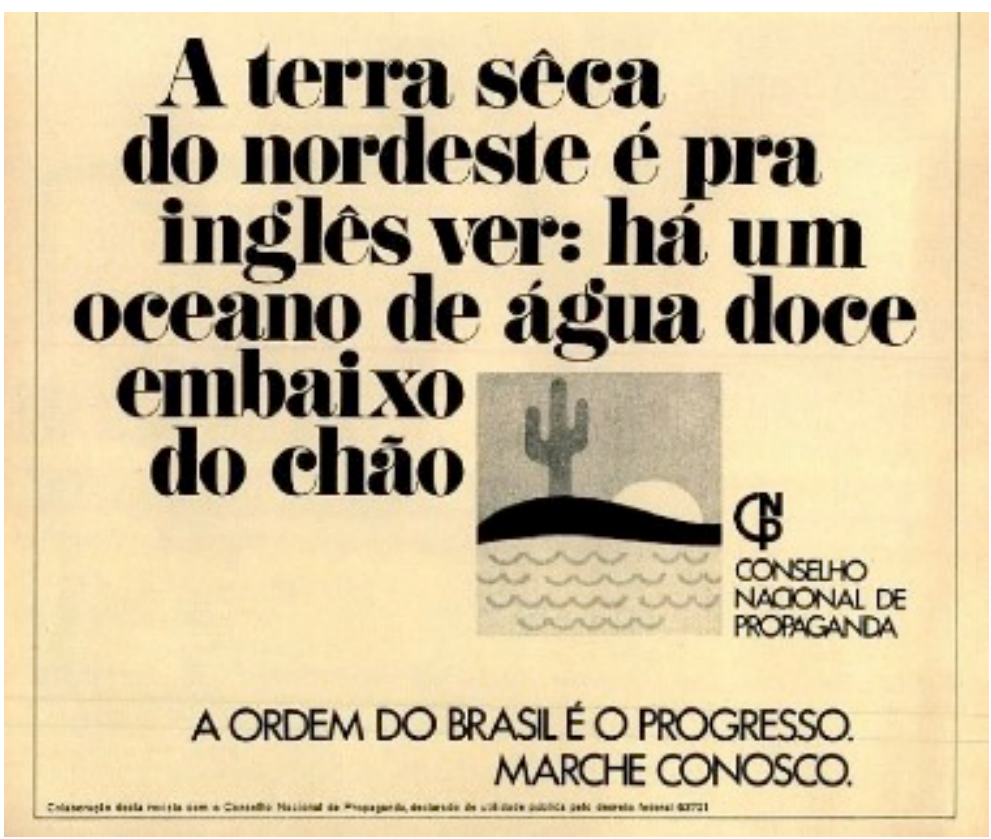

Fonte 2: Revista Veja, abril, 1969, p. 10.

O CNP começava a veicular a ideia que marcaria os "anos de chumbo". Nessa construção, o governo Goulart e, em última análise, os governos civis foram entendidos como caóticos e incapazes de conduzir o Brasil no cumprimento do seu "destino glorioso". Por sua vez, os governos militares, ao implantarem a "ordem", pautada pela "hierarquia", teriam como resultado o sucesso econômico.

Nesta linha de raciocínio, o progresso seria um produto da autoridade imposta pela ditadura militar. A partir de tal perspectiva, os governos civis seriam marcados pela má gestão administrativa, os partidarismos políticos, além das mazelas da corrupção. Por sua vez, o governo acreditava operar fora de tais marcos, promovendo o que acreditavam ser uma gestão racional.

Esse raciocínio sugere uma leitura simplista dos conceitos de autoridade e autoritarismo. Como sugere Hannah Arendt (2016), o exercício da autoridade é confundido com a manifestação de algum tipo de poder e a exigência do uso de alguma forma de violência, física ou simbólica. 
Para Arendt, a autoridade prescinde de qualquer forma de violência, uma vez que opera nos marcos da persuasão argumentativa, o que pressupõe uma igualdade de posições de fala. 0 autoritarismo, por sua vez, opera nos marcos da hierarquia e da repressão, e a obediência, portanto, é obtida tanto pela opressão quanto pela desigualdade do lugar de fala:

Contra a ordem igualitária da persuasão ergue-se a ordem autoritária, que é sempre hierárquica. Se a autoridade deve ser definida de alguma forma, deve sê-lo, então, tanto em contraposição à coerção pela forma como à persuasão através de argumentos. (A relação autoritária entre o que manda e o que obedece não se assenta nem na razão comum nem no poder do que manda; o que eles possuem em comum é a própria hierarquia, cujo direito e legitimidade ambos reconhecem e na qual ambos têm seu lugar estável predeterminado). (ARENDT, 2016, p. 133)

A campanha dialogava com o nacionalismo típico da ditadura militar ao ressaltar a potencialidade do território nacional, ao mesmo tempo em que convocava a população a "marchar conosco". Esse nacionalismo pode ser analisado numa escala ascendente, cujo auge seria nos anos 1970, tanto na forma do "nacionalismo ingênuo" do "País que vai pra frente!”, quanto no formato autoritário do "Brasil: ame-o ou deixe-o!”, patrocinado pela Operação Bandeirantes (OBAN) ${ }^{5}$.

As agências e as instituições de classe procuraram, cada vez mais, participar ativamente do "novo governo". Em meio aos debates da preparação para o II Congresso Brasileiro de Propaganda (23 - 28 de fevereiro de 1969), alguns líderes da propaganda brasileira se manifestaram, tanto no sentido de defender a propaganda das possíveis interferências do Estado (censura) quanto das possibilidades de sua utilização como parte fundamental para o sucesso do país.

Em entrevista publicada pela revista Propaganda, Renato Castelo Branco (diretor da J. W. Thompson e um dos fundadores do CNP) reivindica para a propaganda a capacidade de "ilustrar" as massas:

\footnotetext{
5 Criada em 1969, tinha sede no 2º Batalhão de Reconhecimento Mecanizado da Polícia do Exército, na capital paulista. Sua ação era articulada com a Dops, Exército, Marinha e Aeronáutica. Seu objetivo era integrar a repressão contra os partidos de extrema esquerda, ainda realizada de maneira fragmentada pelas diversas agências. A OBAN conseguiu financiamento de diversos empresários paulistas por meio da atuação da FIESP. Em março de 1970, no governo Médici, sua atuação foi ampliada por meio da criação do sistema DOI-CODI.
} 
Um dos maiores problemas da sociedade moderna", prosseguiu Castelo, "é a comunicação. Do produtor com o consumidor, do empregador com o empregado, do professor com o aluno, dos pais com os filhos, do Govêrno com o povo. Comunicar bem é um dos grandes segrêdos do êxito em nossa sociedade. E a propaganda é, por excelência, a técnica de comunicar. $\mathrm{Na}$ atual fase da evolução social do Brasil, poucas atividades poderiam dar uma contribuição mais decisiva. Há uma necessidade urgente de informar ao povo, em todos os setores: econômico, social e político. E os caminhos do povo vão depender, em grande extensão, da capacidade dos dirigentes de informá-lo, educá-lo, através da comunicação6 ${ }^{6}$.

Em seguida registra a importante participação da propaganda brasileira na aceleração e no aumento do desenvolvimento econômico. Para Renato Castelo Branco, a propaganda merecia um lugar de destaque na história nacional:

Ainda está por ser devidamente estudado o papel que os homens de propaganda desempenharam no estímulo e aceleramento dêste processo evolutivo. Mas um dia, na história do desenvolvimento industrial e comercial do Brasil, haverá um importante capítulo dedicado à contribuição dos publicitários, neste quarto de século, para o desenvolvimento das indústrias, para o lançamento e aprimoramento de produtos, para a difusão de novos hábitos, para a educação do consumidor e a expansão do mercado brasileiro ${ }^{7}$.

Os objetivos apontados por Renato Castelo Branco estavam em acordo com várias das observações do Manual Básico da Escola Superior de Guerra. Permanecia a ideia de que este sujeito amorfo, chamado de "povo", deveria ser guiado e tutelado e, se assim o fosse, Renato Castelo Branco abriria as portas para a contribuição da propaganda em tal empreitada.

Outro destaque relevante era a necessidade de a propaganda deixar sua marca na execução do projeto "Brasil potência". O apelo final do diretor do CNP era para que os publicitários participassem, de fato, da política nacional:

Proponho que os homens de propaganda sejam mobilizados para o estudo dos problemas de comunicação internos e externos do país: para os esforços nacionais de promoção, nas áreas de turismo, exportação e propaganda no exterior. Para funções de assessoria e funções executivas adequadas nos Ministérios e Governos dos Estados e da União8.

Em janeiro de 1968, Mauro Salles (Salles-Interamericana), enquanto presidente da Associação Brasileira de Propaganda (ABP), já apresentava as qualidades da propaganda brasileira e a intensa participação desta na vida nacional:

\footnotetext{
${ }^{6}$ Revista Propaganda, $\mathrm{n}^{\mathrm{o}}$ 145, junho 1968, p. 24.

7 Idem.

8 Idem.
} 
A propaganda no Brasil é uma atividade econômica que aplica 500 milhões de cruzeiros novos por ano para ajudar a indústria e o comércio a vender os seus produtos. Somos os profissionais da prosperidade, os aceleradores do desenvolvimento, os multiplicadores de riqueza, os educadores do bem-estar, os apologistas da competição sadia, os sentinelas avançados da livre emprêsa. Os nossos estudos, as nossas pesquisas, os nossos planejamentos são cada vez mais necessários em um mercado que aos poucos se despede de uma inflação mutiladora. Os nossos investimentos na imprensa, no rádio, na televisão se constituem em favor imprescindível à sobrevivência da liberdade de expressão, sem a qual não sobrevive um regime democrático 9 .

A projeção de resultados econômicos positivos para o início da década de 1970 manteve elevado o otimismo das agências. Várias delas encamparam as campanhas do CNP que procuravam engrandecer as riquezas nacionais, o trabalho e a coragem dos empresários. Colocavam-se, assim, em defesa dos benefícios da "revolução de 1964". Dois anúncios retratam com clareza o espírito daquele tempo. 0 primeiro, intitulado "0 Brasil está à beira do abismo", foi publicado em 1969 pela Salles-Interamericana, e ocupou a página inteira no "Jornal do Brasil".

\footnotetext{
9 Mauro Salles. Discurso pronunciado em nome da Associação Brasileira de Propaganda na "Festa da Propaganda", realizada no Rio de Janeiro em homenagem ao Dia Pan-americano de Propaganda. In: Revista Propaganda, nº 140, janeiro de 1968, p. 58.
} 


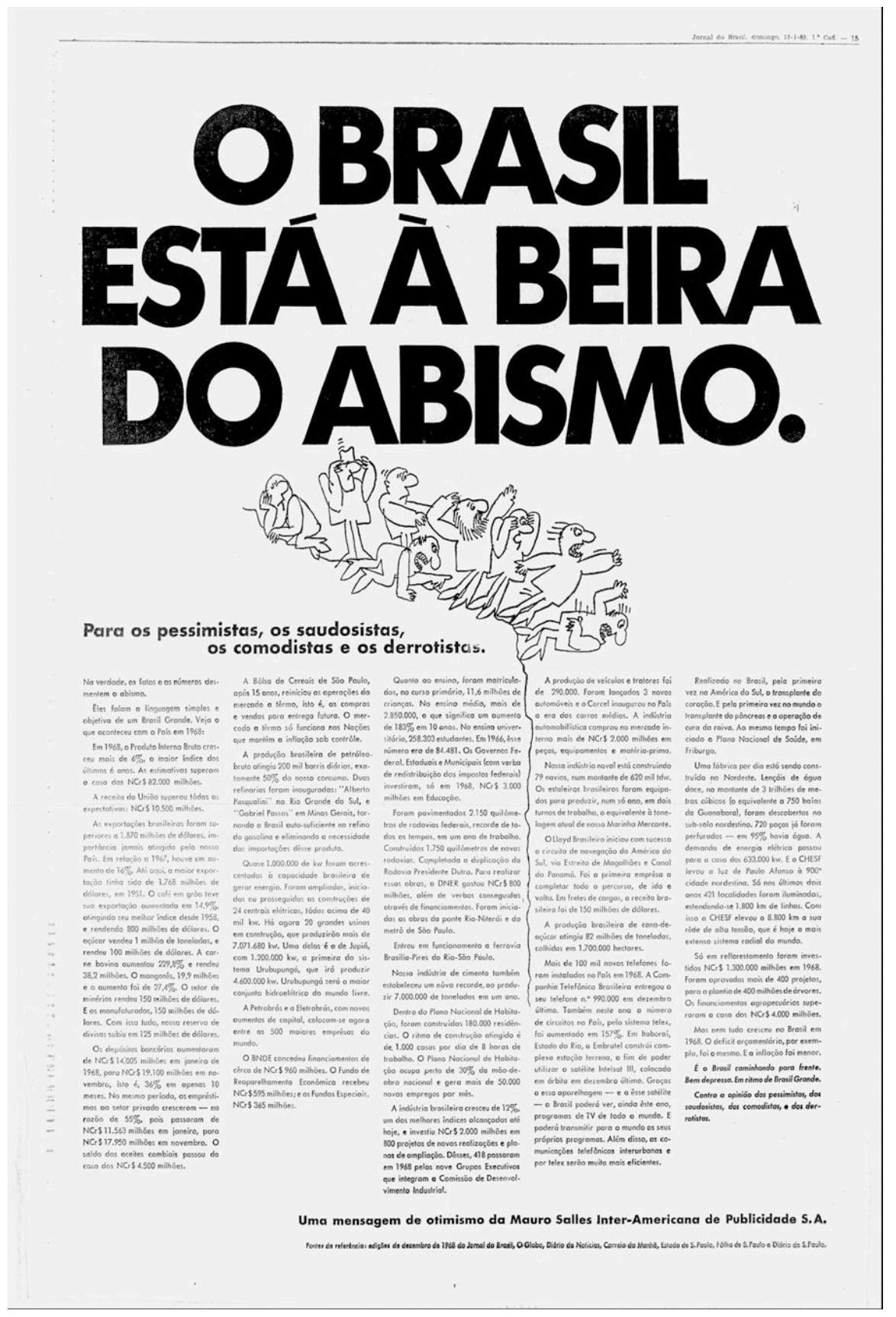

Fonte 3: Jornal do Brasil, 12/01/1969.

Inspirado em anúncio parecido ao da APP, a agência procurou desconstruir o "mito" de que o país estava enfrentando dificuldades. O subtítulo do anúncio, "para os pessimistas, saudosistas, os comodistas e os derrotistas", indicava o "público alvo". No decorrer do anúncio eram desconstruídas as "versões" do esgotamento econômico e apresentados aqueles que "falam a linguagem simples e objetiva de um Brasil Grande". 
A análise do anúncio demonstra que a agência fazia o papel de um órgão estatal de propaganda (ainda que a AERP já estivesse em funcionamento), e trazia informações como o crescimento do PIB, receita da União, exportações, aumento de depósitos bancários, resultados agrícolas, misturadas com os resultados dos índices de escolaridade, pavimentação de rodovias e construção de ferrovias.

O último parágrafo é uma assertiva contra aqueles que se recusavam a trabalhar pelo Brasil: "É o Brasil caminhando para frente. Bem depressa. Em ritmo de Brasil Grande. Contra a opinião dos pessimistas, dos saudosistas, dos comodistas, e dos derrotistas".

0 anúncio teve grande impacto. A revista Propaganda dedicou um número especial, lançado em janeiro de 1970, para veicular os anúncios premiados em 1969. A campanha da agência recebeu o prêmio de Melhor Anúncio do Ano. De acordo com a revista,

\begin{abstract}
Êste anúncio, publicado nos primeiros dias de janeiro de 1969, foi uma grande manifestação de otimismo e confiança no país e teve o mérito de lançar o slogan "Ritmo de Brasil Grande" que depois foi adotado pelo próprio governo para caracterizar os seus objetivos. Mais de uma centena de anúncios de tôdas as agências utilizaram posteriormente a expressão lançada na peça publicitária que mereceu indicação unânime como o Anúncio do Ano 196910.
\end{abstract}

A história da agência Mauro Salles Publicidade, posteriormente SallesInteramericana, é permeada de ligações políticas. Mauro Salles é filho de Apolônio Jorge de Faria Salles, ministro da Agricultura entre 1942-1945, senador por Pernambuco em 1947, e novamente ministro da Agricultura em 1954, no segundo governo Vargas. Mauro Salles era formado em direito pela Pontífice Universidade Católica do Rio de Janeiro e especialista em jornalismo.

Sua atuação no jornalismo começou na redação das revistas $O$ mundo e Mundo Ilustrado. Em 1950, foi trabalhar como subchefe de reportagem do jornal $O$ Globo, onde mantinha uma coluna sobre automóveis e aviões. Depois, ingressou na Alcântara Machado e passou a cuidar da conta da Volkswagen. Em 1961, assumiu a cadeira de

10 Revista Propaganda, s/no, janeiro 1970, s/p. 
secretário do Conselho de Ministros, durante o período em que Tancredo Neves ocupou o cargo de Primeiro Ministro.

A partir daí, sua carreira na propaganda teve uma escalada impressionante. Em 1964, já era chefe da redação d'O Globo; no ano seguinte, assumiu o cargo de diretor da recém-inaugurada TV Globo. Em 1965, organizou a campanha de lançamento do Aero Willys Luxo, por meio do recém-criado Grupo Técnico de Propaganda. Para a execução da campanha, Mauro Salles introduziu o merchandising no Brasil.

O sucesso da campanha sacramentou a sociedade entre Mauro Salles e a montadora, que entrou com $20 \%$ do capital para a criação da nova agência, a Mauro Salles Publicidade. Aliado à conta da montadora, recebeu clientes como a Associação Brasileira de Cimento Portland, a Castrol do Brasil e a Companhia Guanabara de Crédito. Em 1967, a Mauro Salles Publicidade fundiu-se com a Armando D’Almeida, surgindo a Mauro Salles-Interamericana de Publicidade S/A.

Em 1967, passou a dirigir a revista Propaganda e foi eleito o presidente da Federação Brasileira de Publicidade e da Associação Brasileira de Propaganda, onde ficou até 1969. Foi o principal articulador do II Congresso Brasileiro de Propaganda, realizado em 1969. Em 1970 foi eleito o Homem de Propaganda, e em 1972 recebeu o prêmio Publicitário do Ano. Em 1977, em meio a tentativas de se censurar a propaganda, foi um dos principais responsáveis pela elaboração do Código Brasileiro de Autoregulamentação Publicitária (CONAR), sendo o seu primeiro relator. Na década de 1980, Mauro Salles foi um dos líderes da campanha de Tancredo Neves, sendo o organizador do Comitê Nacional Publicitário Pró-Tancredo Neves.

Mauro Salles, portanto, foi um ator histórico que sempre permaneceu próximo às instâncias de decisão política, fosse no governo Goulart (quando foi ministro da Indústria e Comércio), durante os anos da ditadura militar (veiculando mensagens de otimismo como essa) ou já no desmonte da ditadura (com a intensa participação na campanha eleitoral de Tancredo Neves).

O anúncio que destacamos apresenta um aspecto importante da relação agênciasditadura. Existe, evidentemente, uma explicação econômica - a proximidade mantém o 
acesso às contas públicas -, porém também uma explicação ideológica - o alinhamento político entre as agências e a ditadura. Em 1975, a revista Veja veiculou uma reportagem sobre o que os empresários esperavam do governo Ernesto Geisel. Caio Alcantâra Machado, sócio de Mauro Salles na agência, respondeu: "segurança, somente segurança"11.

Os vínculos ideológicos entre as agências, o golpe e a ditadura militar podem ser observados em todo o período, embora em alguns casos sejam mais claros, como o da Norton Propaganda S/A. É possível rastrear o papel da agência desde o contexto imediatamente anterior ao golpe militar de 1964.

O fundador da empresa, Geraldo Alonso, era membro ativo da seção paulista do Ipes (Instituto de Pesquisa e Estudos Sociais). Em conjunto com outras agências, organizava, junto aos anunciantes, o desvio das verbas de propaganda para o instituto. Dreifuss (2008, p.221-222), ao analisar a organização da contribuição para o Ipes, afirma:

Uma forma muito importante de camuflar as doações era através de empresas de relações públicas e de propaganda que controlavam os chamados "orçamentos invisíveis" de grandes corporações, orçamentos estes que representavam vultosas somas de dinheiro. 0 que as companhias poderiam fazer seria canalizar suas participações através de fundos assinalados como orçamentos para propaganda comercial e relações públicas por meio das agências que apoiavam o IPES. Outra alternativa seria as grandes empresas pagarem antecipadamente os seus contratos de doze meses com as agências de relações públicas, que daí canalizariam os fundos, bem como contribuiriam financeiramente com suas próprias fontes. Tal operação não seria muito complexa, já que muitos dos associados do IPES eram proprietários ou diretores de agências de publicidade e manipulavam as contas de corporações multinacionais e associadas, cujos donos dirigentes também eram associados do IPES.

Dreifuss (2008) destaca ainda diversos diretores de agências que participavam de reuniões e ofereciam seus serviços. Segundo o autor, foi José Luiz Moreira de Sousa (Denisson Propaganda12) que "ofereceu seus préstimos para operar como um conduto

\footnotetext{
${ }^{11}$ As reações dos empresários. Revista Veja, no 359, p.81. Apud: Rezende, 2001, p.176.

12 A Denison foi fundada no Rio de Janeiro, em 1957, por J. U. Arce e Sepp Baendereck. Surgiu como uma house agency e atendia apenas a conta da Ducal, uma cadeia de lojas de roupas masculinas. A expansão da rede facilitou a ampliação da agência, que passou a contar com novos clientes, como a Swif e a gravadora RCA Victor. Em 1958, abriu filial em São Paulo, e, em 1962, em Belo Horizonte. Em 1970, já havia aberto filiais em Porto Alegre, Salvador, Recife e Fortaleza. Após a formação do Consórcio Brasileiro das Agências de Propaganda, passou a fazer parte do grupo batizado "As Cinco Irmãs".
} 
para a 'limpeza do dinheiro"”, e "não sentiria o menor constrangimento em receber as somas através de sua agência de Propaganda e depois devolvê-las ao Ipes" (DREIFUSS, 2008, p. 222). Além da Denisson Propaganda, tiveram esse mesmo tipo de atuação a Gallas Propaganda, Norton Propaganda e Multi Propaganda13.

A outra ponta dessa relação, ou seja, os anunciantes, era organizada tendo em vista a manutenção de suas contas naquelas agências que tinham algum tipo de atuação no Ipes. Ainda de acordo com Dreifuss (2008), este foi o caso da Willys Overland, cujo diretor, Euclides Aranha, era líder do Ipes. A conta da Willys era operada por duas agências "ipesianas": a Multi Propaganda, de propriedade de David Monteiro, e a Norton Propaganda. Outro caso que vale o destaque era o da Nestlé. Seu diretor, Gualter Mano, também associado do Ipes, mantinha a conta da empresa junto à Norton Propaganda S/A e à McCann-Erickson Propaganda.

Outro apoio ao Ipes veio das instituições de classe da propaganda. David Monteiro $^{14}$ e Geraldo Alonso alternavam-se na presidência da Associação Paulista de Propaganda (APP) e da Federação Brasileira de Propaganda (Febrasp), criada em 1961. Utilizando-se dos cargos, aproximavam-se das agências, procurando apoio. Valendo-se dessa relação conseguiram, por exemplo, o apoio de Emil Farhat ${ }^{15}$, da McCann-Erickson Publicidade.

Todo esse esforço de coleta, desvio e aplicação dos recursos teve como resultado, por um lado, o financiamento das atividades do Ipes e, por outro, o massacre midiático que João Goulart sofrera durante o seu curto mandato presidencial. A atuação do IPES e

\footnotetext{
${ }^{13}$ A agência foi fundada em 1958 pela McCann Erickson. Sua existência foi muito curta; em 1966 assumiu o nome de Quadrant Publicidade, com o objetivo de melhorar sua identificação internacional, e em 1972 a agência encerrou suas atividades.

${ }^{14}$ Sua trajetória na propaganda começou em 1935, quando a agência norte-americana McCann Erickson se instalou no Brasil. Ao lado de Renato Castelo Branco, foi um dos primeiros redatores da agência. Em 1951, a McCann converteu-se em sociedade anônima, e Monteiro assumiu vice-presidência ao lado de Emil Farhat. Atuou na criação da Associação Paulista de Propaganda, sendo presidente da instituição em dois momentos, 1939-1940 e 1959-1961. Em 1958 deixou a McCann para atuar na Multi Propaganda. Também teve destaque na criação do Conselho Nacional de Propaganda, sendo eleito presidente do conselho em 1966.

15 Teve extensa atuação na história da propaganda brasileira. Em 1941, ingressou na McCann Erickson, permanecendo na agência por 31 anos. Entre seus destaques, está a criação dos slogans do Repórter Esso: "O primeiro a dar as últimas" e "Testemunha ocular da história". Em 1969, tornou-se presidente da agência, e assumiu a Secom (Secretaria de Comunicação da Presidência da República) entre 1978 e 1980.
} 
de seu "irmão", o Ibad, foi alvo de CPI, e sua atuação na desestabilização do governo civil está amplamente documentada ${ }^{16}$.

Os vínculos ideológicos entre Ipes, agências e anunciantes edificaram uma associação que foi além dos preparativos para o golpe militar. Essa teia de relações exercia verdadeiro controle sobre os veículos, à medida que controlava parte das receitas em propaganda.

Como sustenta Chomsky (2003), a forma mais eficiente e mais "limpa" de censura é o controle econômico. Desta forma, diversos veículos considerados próximos ao governo João Goulart e críticos à ditadura tinham campanhas publicitárias retiradas, o que afetava em cheio a saúde financeira. Esse tipo de controle econômico era (e continua sendo) muito mais efetivo - e discreto - do que a intervenção direta do Estado.

Vejamos o caso do Tribuna da Imprensa: em 31 de março de 1969, o jornal publicou reportagem intitulada "Boicote". De acordo com o texto, existia no Brasil uma “...batalha da opinião pública, travada pelos conglomerados econômicos norteamericanos, no sentido de nos convencer de que a 'solução está nos Estados Unidos'”17.

A denúncia do jornal estava vinculada à forma como o capital estrangeiro interferia na sociedade brasileira. Além das agências estrangeiras J. W. Thompson, McCannErickson e a Lintas Publicidade Internacional (até então as líderes do ranking nacional), outras agências nacionais cooperavam com aquilo que o jornal considerava "proselitismo" e "venda sub-reptícia e constante de um certo 'way of life"”.

São apresentadas, ainda, denúncias a respeito do controle exercido sobre os meios de comunicação, via verbas publicitárias:

Quem não conhece o caso repetidamente por nós mencionado da série de reportagens de Justino Martins, em "Manchete", sôbre a União Soviética? Bastou a ABA (Associação Brasileira de Anunciantes), que é virtualmente controlada pelos conglomerados norte-americanos, telefonar à direção da

\footnotetext{
${ }^{16}$ A CPI Ipes/Ibad procurou analisar o financiamento de campanhas eleitorais de deputados e senadores com dinheiro das doações. Em 1963 a CPI apurou que 3\% das agências controlavam 45\% do mercado. Por meio dessas agências, altas quantias em dinheiro eram transferidas para os fundos do Ipes. Além do estudo de Dreifuss (2008), ver Assis (2001)

170 boicote. Tribuna da Imprensa, 31 de março de 1969.
} 
revista, dizendo: "se continuar a série, seremos obrigados a recomendar aos nossos associados para boicotar (verbozinho indecente!) sua revista"18.

Ainda de acordo com o periódico, esse tipo de política alcançou as contas públicas:

0 anúncio de página inteira que a MPM Propaganda distribui à imprensa, promovendo as realizações do governador Negrão Lima, exclui acintosamente o tradicional "Correio da Manhã", que, em tiragem, é o terceiro maior vespertino da Guanabara e em matéria de folha de serviços prestados a êste Páis não tem competidor entre os matutinos cariocas. É o boicote com que se leva aquela emprêsa a pedir concordata, forçando sua direção, por todos os meios e modos, a abrir mão de posições políticas que resultam de convicções herdadas de seus fundadores e que, longe de serem tão brutalmente esmagadas, deveriam ser apreciadas e compreendidas...

O controle econômico demonstra uma rede de relações que envolvia diversos grupos políticos que, por sua vez, formavam o grupo heterogêneo que dava sustentação política à ditadura militar. Reconhecer tais movimentos, como sugerem Rollemberg e Quadrat (2010), é desvendar que tipo de vínculos sociais foram/são estabelecidos entre os regimes políticos e as sociedades. Tais redes, embora sofressem alterações tendo em vista a variedade de sua constituição, apontam para um conjunto maior de apoio que tais regimes obtiveram para além do uso da violência física.

O fator a ser compreendido é que as campanhas levantadas demonstram uma tentativa deliberada de algum tipo de manipulação emotiva. Como sugerem Ansart (1977) e Magalhães (1997), os regimes políticos necessitam criar imagens que incitem o conjunto daqueles sentimentos tidos como essenciais para manter a mobilização social ativa a seu favor. No caso em tela, as campanhas procuram insuflar elementos como o "patriotismo" e o "nacionalismo", sempre entendidos como manifestações apolíticas na defesa dos interesses nacionais e não daqueles que ocupam seus cargos.

Ansart (1977), ao analisar as diferentes formas de trabalho ideológico (onde opera-se a violência simbólica e não a física), as classificou em três tipos: ortodoxia apoiada (quando as mensagens são produzidas e apoiadas, na maioria das vezes, de maneira instantânea); ortodoxia consentida (forma organizada e sistematizada de produção de informações e controle sobre a opinião pública); e ortodoxia terrorista

18 Idem. 
(quando o discurso é substituído pelos mitos). Estes três elementos dialogam, produzindo diversos discursos de legitimação.

No caso a seguir, essa tipologia foi assumida não pelo Estado Autoritário, mas por seus apoiadores da sociedade civil. Superado o golpe, a Norton Propaganda S/A procurou demonstrar a continuidade do seu apoio ${ }^{19}$ a partir da criação de uma campanha em favor do novo "presidente", Costa e Silva. Veiculada em 1967, o objetivo era defender o governo num momento de instabilidade política e econômica e manter o "estado de otimismo". A campanha ficaria registrada pela utilização da bandeira do Brasil e pelo slogan: "Quem planta confiança colhe progresso!”:

Figura 4: Campanha "Quem semeia confiança colhe progresso":

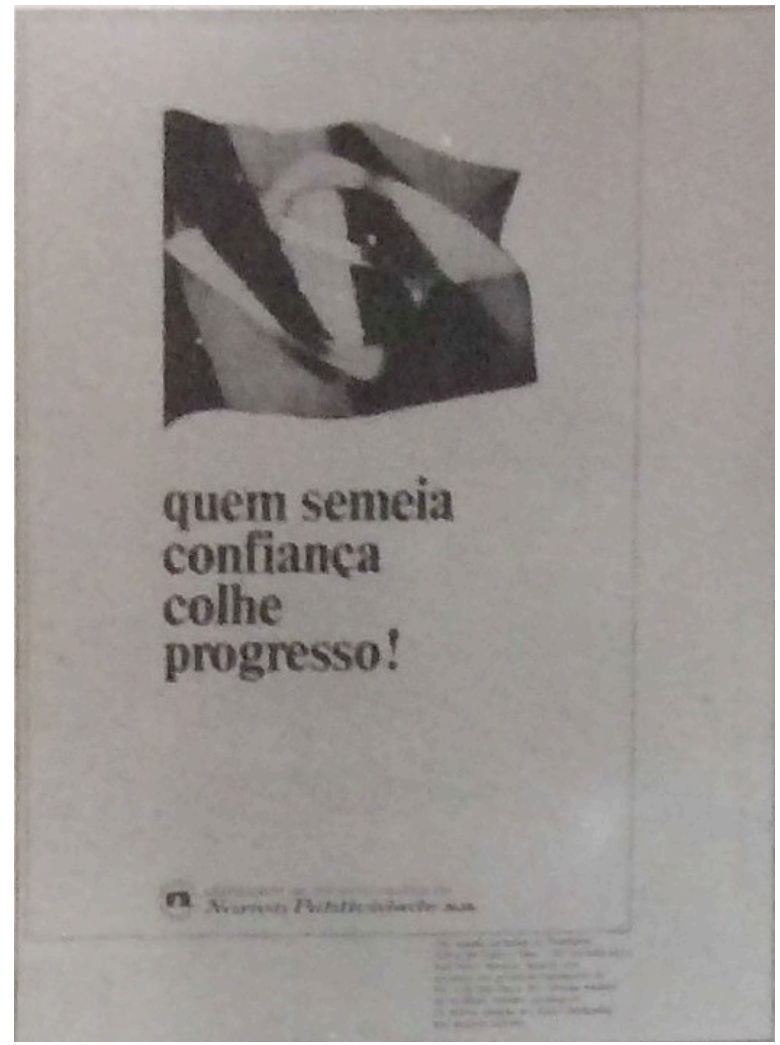

Fonte 4:Revista Propaganda, 1981, p.36.

\footnotetext{
${ }^{19}$ Não nos parece errôneo afirmar a permanência ou continuidade do suporte ideológico à ditadura por parte da agência. A campanha apresentada foi veiculada em 1967, portanto, quase um ano antes da criação da AERP e quase dois anos antes do surgimento do Consórcio Brasileiro das Agências de Propaganda, responsável pela “divisão” das contas públicas.
} 
Na sequência, o anúncio ia além e adotava o padrão de um órgão oficial de propaganda. 0 que chama atenção é, exatamente, o tom personalista que a campanha apresentou. Em nossas pesquisas, foi a única encontrada nesse formato. A Norton utilizou uma linguagem que não faria vergonha ao DIP de Getúlio Vargas.

Figura 5: Campanha "Quem semeia confiança colhe progresso":

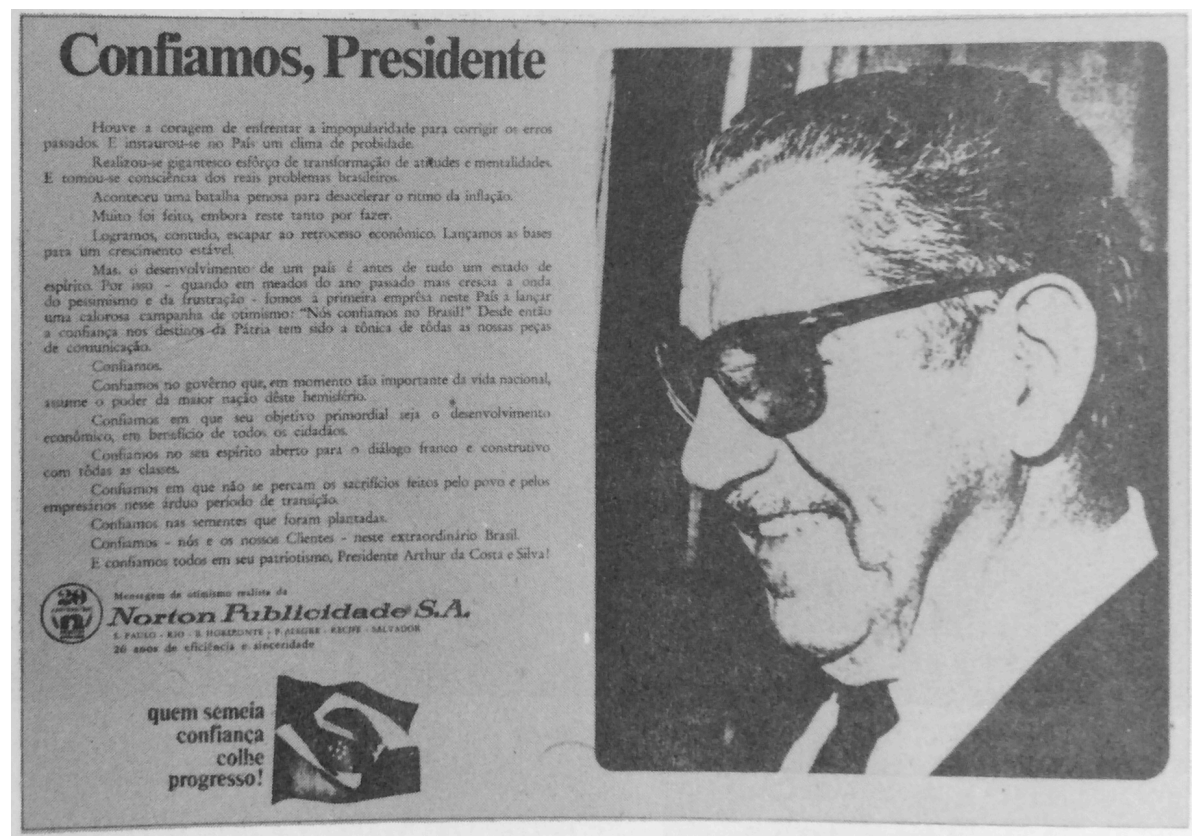

Fonte 5: Correio Braziliense, 22 de março de 196720.

A campanha da Norton chama a atenção não apenas pela forma personalista que utiliza, pelos apelos à capacidade do presidente de superar a "impopularidade", mas, também, por romper a barreira entre a propaganda e a publicidade praticada por uma

\begin{abstract}
${ }^{20}$ Transcrição: Houve a coragem de enfrentar a impopularidade para corrigir os erros passados. E instaurou-se no País um clima de probidade. Realizou-se gigantesco esforço de transformação de atitudes e mentalidades. E tomou-se consciência dos reais problemas brasileiros. Aconteceu uma batalha penosa para desacelerar o ritmo da inflação. Muito foi feito, embora tanto por fazer. Logramos, contudo, escapar ao retrocesso econômico. Lançamos as bases para um desenvolvimento estável. Mas, o desenvolvimento de um país é antes de tudo um estado de espírito. Por isso - quando em meados do ano passado mais crescia a onda de pessimismo e da frustração fomos a primeira emprêsa neste País a lançar uma calorosa campanha de otimismo: "Nós confiamos no Brasil" Desde então a confiança nos destinos do País tem sido a tônica de todas as nossas peças de comunicação. Confiamos. Confiamos no governo que, em momento tão importante da vida nacional, assume o poder da maior nação dêste hemisfério. Confiamos em que seu objetivo primordial seja o desenvolvimento econômico, em benefício de todos os cidadãos. Confiamos no seu espírito aberto para o diálogo franco e construtivo com tôdas as classes. Confiamos em que não se percam os sacrifícios feitos pelo povo e pelos empresários nesse árduo período de transição. Confiamos nas sementes que foram plantadas. Confiamos - nós e os nossos Clientes - neste extraordinário Brasil. E confiamos todos em seu patriotismo, Presidente Arthur da Costa e Silva!
\end{abstract}


agência comercial. Outros apelos são feitos em nome da "capacidade de diálogo" de Costa e Silva e de seu "patriotismo". Gostaríamos de ressaltar o apelo "ao estado de espírito":

\begin{abstract}
Mas, o desenvolvimento de um país é antes de tudo um estado de espírito. Por isso - quando em meados do ano passado crescia a onda de pessimismo e da frustração fomos a primeira emprêsa neste País a laçar uma calorosa campanha de otimismo: "Nós confiamos no Brasil!" Desde então a confiança nos destinos da Pátria tem sido a tônica de todas as nossas peças de comunicação. Confiamos - nós e nossos Clientes - neste extraordinário Brasil.
\end{abstract}

A campanha obteve tanto sucesso que o então presidente Costa e Silva recebeu Geraldo Alonso para uma solenidade em Brasília para receber em mãos os pôsteres e anúncios vinculados. A revista $O$ Cruzeiro de janeiro 1972 fez matéria especial sobre Geraldo Alonso. Ao tratar da campanha, a revista afirma que a agência "partiu em ajuda do Govêrno, levando o otimismo às massas populares".

A atitude de "socorro" da Norton tinha relação com os problemas enfrentados por Costa e Silva durante seu mandato. Em seu discurso de posse, acenou com a promessa de reestabelecimento dos processos eleitorais, do retorno à normalidade democrática e com disposição para receber e dialogar com a oposição.

Essa tentativa, conceituada de "política de alívio" por Alves (2005), tinha como pedra angular uma interpretação mais flexível da legislação repressiva, contida na Constituição de 1967. Após algumas reuniões, o governo pareceu oferecer algumas concessões à oposição em troca de algum tipo de apoio e legitimidade.

Entretanto, naquele contexto, o governo detinha instrumentos que tornavam o diálogo com a oposição desnecessário. Além da garantia da maioria nas casas legislativas, contava ainda com o instrumento do decurso de prazo. Outro problema irremediável era a atuação do aparato repressivo e da Polícia Militar, ou seja, enquanto o governo pregava diálogo, a repressão aumentava suas ações. Em suma:

A contradição entre linguagem do consenso e do diálogo e o aumento da repressão nas ruas anulou a legitimidade que se esperava obter com a promessa de liberalização. Como a "política de alívio" dependia de um grau de consenso impossível em condições repressivas, o Estado evoluiu para uma situação de crise interna e externa. Também na política econômica verificou-se ligeira mudança de rumos. A equipe econômica do governo Costa e Silva era chefiada pelo Ministro da Fazenda Delfim Netto e pelo Ministro do 
Planejamento Hélio Beltrão. (...) A nova política econômica visava sobretudo alterar o padrão de consumo das classes médias superiores para promover o crescimento do setor de bens duráveis. E enquanto se atrelavam os níveis salariais à taxa oficial de inflação, para diminuir os custos de produção, incentivos fiscais eram concedidos às camadas mais altas da população para incentivar o investimento (ALVES, 2005, p. 138).

Em termos econômicos, a política salarial foi um desastre. 0 salário mínimo real comprava apenas $42 \%$ do que poderia comprar em 1959. A tendência foi uma queda constante até atingir o valor mais baixo em 1976, quando seu potencial de compra era de apenas 31\%, comparado ao salário de 1959. Se compararmos os dados referentes à inflação, podemos compreender que a queda no valor do salário era uma política de controle exercida pelo próprio Estado, uma vez que a inflação baixou de 87.8\% em 1964 para $20.3 \%$ em 1969.

0 resultado foi o aumento da miséria entre os mais pobres. Aproveitando esse cenário, a Norton veiculou, em 1969, mais um anúncio, ainda dentro da campanha "Quem semeia confiança colhe progresso", agora voltado para a ajuda às crianças carentes: 
Figura 6: Campanha "Quem semeia confiança colhe progresso":

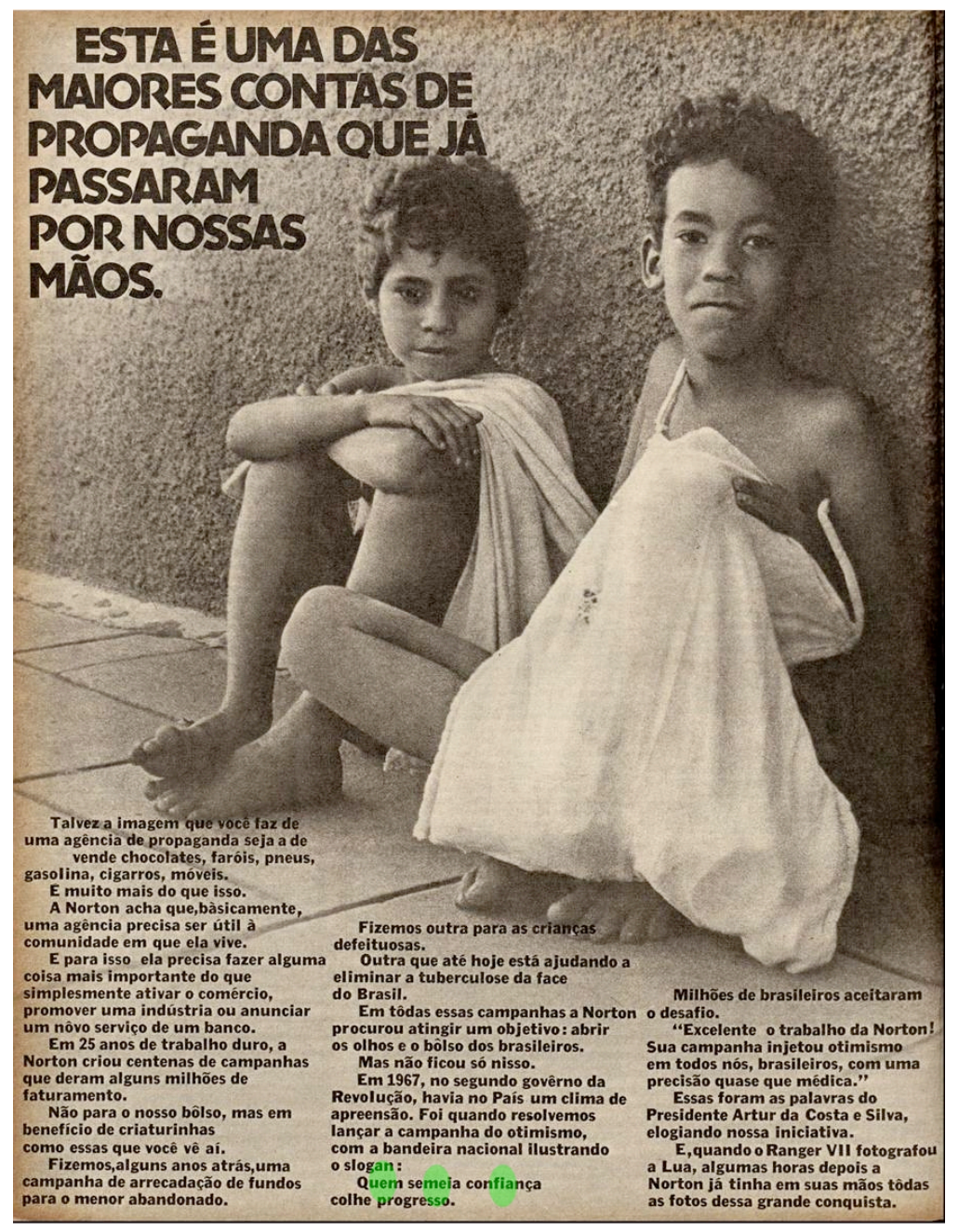

Fonte 6: Revista Propaganda, novembro, 1981, p.36.

Entre os objetivos da campanha estava aquele atrelado ao "papel social" da propaganda. Como afirma o texto do anúncio:

A Norton acha que, basicamente, uma agência precisa ser útil à comunidade em que ela vive. Fizemos, alguns anos atrás, uma campanha de arrecadação de fundos para o menor abandonado. Fizemos outra para as crianças defeituosas. Outra que que até hoje está ajudando a eliminar a tuberculose do Brasil.

A Norton procurava, assim, firmar seu "compromisso histórico" com o bem-estar do Brasil e dos brasileiros. Aproveitava o ensejo, ademais, para recuperar a ótima resposta dada pelo então presidente Costa e Silva a respeito do lançamento da campanha em 1967: 
Em 1967, no segundo gôverno da Revolução, havia no país um clima de apreensão. Foi quando resolvemos lançar a campanha do otimismo, com a bandeira nacional ilustrando o slogan: Quem semeia confiança colhe progresso.

Milhões de brasileiros aceitaram o desafio.

"Excelente trabalho da Norton! Sua campanha injetou otimismo em todos nós, brasileiros, com uma precisão quase médica". Essas foram as palavras do Presidente Artur da Costa e Silva, elogiando a nossa iniciativa.

Em outro anúncio, então de página dupla, a agência afirmava não medir esforços para ajudar a solucionar os problemas brasileiros, uma vez que "nessa hora a Norton desvia tôda sua equipe, todo seu talento e tôda sua estrutura, para preparar uma campanha com a mesma seriedade com que ela faz as campanhas de todos os seus clientes"21.

É evidente que a agência não entendia a resolução desses tipos de problemas sociais enquanto parte da urgência da criação de políticas públicas ou mesmo enquanto produtos do modelo econômico colocado em prática após 1964; ao que parece, era pura e simplesmente a prática do exercício da filantropia, questão de caridade e de solidariedade.

O governo Costa e Silva teve de lidar também com a ofensiva da oposição. Essa onda começou a formar-se em 1967, para erguer-se em 1968, tendo, entre outros eventos, a Passeata dos Cem Mil, ocorrida após a morte do estudante Edson Luís, e as primeiras greves em Contagem e Osasco, além da Frente Ampla, que organizava, sob a mesma bandeira, João Goulart, Juscelino Kubitscheck e Carlos Lacerda.

Paralelo a esse movimento, existia o discurso do "Brasil Potência", parte do nacionalismo exacerbado das Forças Armadas, insuflado em meio aos planos de investimento em infraestrutura (como Itaipu e a Transamazônica). Contudo, as agências de propaganda se anteciparam ao sucesso econômico dos anos 1970-1974 ao propagar esse "projeto" ainda em 1967, como o caso da Norton, e em 1969, no caso da SallesInteramericana, além da atuação do próprio Conselho Nacional de Propaganda.

Parece reducionismo afirmar que essa "primeira fase" tenha sido marcada apenas pelos interesses econômicos. A distribuição das contas governamentais para atender a

${ }^{21}$ Revista Propaganda, novembro, 1981, p. 36. 
demanda da AERP só traria impacto para as agências a partir de $1975^{22}$, quando o ranking nacional das agências sofre uma mudança significativa. Outro elemento dessa equação é apontado pelos próprios publicitários. Renato Castelo Branco, ainda em 1968, já cobrava do setor uma aproximação maior com a União, Estados e municípios:

Proponho que nossas associações de classe tomem posição diante dos problemas nacionais e especialmente daqueles para os quais podemos dar uma contribuição válida. Proponho que abandonemos a posição marginal em que nos temos colocado para assumirmos um lugar definitivo e influente nas decisões da vida nacional. Proponho que estejamos presentes nos Congressos Estaduais e Federal, nas Secretarias de Estado, nos Ministérios, levando, sem intermediários, mas nós próprios, nossa contribuição para a solução dos problemas nacionais ${ }^{23}$.

Mauro Salles, então presidente da ABP, destacou a importância da cooperação com o "novo governo", à medida que as agências deveriam responder positivamente ao "chamado":

A Associação Brasileira de Propaganda, a Associação Brasileira de Agências de Propaganda têm sido procurados por pessoas e entidades do governo que se mostram interessadas em cooperar com os publicitários em sua missão de reativar a vida econômica. Mas precisaremos cooperar com êles, ajudando-nos a nós mesmos ${ }^{24}$.

A cooperação com o governo, ainda que tenha sido iniciativa de algumas agências, ganhou relevância, tendo em vista a posição tanto da Salles-Interamericana quanto da Norton Propaganda S/A no mercado publicitário brasileiro. As campanhas foram veiculadas, ao que tudo indica, numa espécie de "esforço coletivo" das agências e, de fato, não representavam a totalidade do mercado publicitário brasileiro, ainda que, como destacamos, outras agências de importância nacional tenham participado do contexto anterior ao golpe, como a Denison Propaganda e as duas maiores agências, a McCann Erikson e a J. W. Thompson.

\footnotetext{
22 Outro dado a ser apontado é que somente as agências com mais de 50\% de capital nacional poderiam participar das licitações das contas públicas, o que significou, a partir de 1974, a transformação do mercado de agências, com o fortalecimento das agências nacionais. Posteriormente, visando monopolizar o acesso a estes recursos, foi criado o Consórcio Brasileiro de Agências de Propaganda, formado pelas cinco maiores agências nacionais, as "Cinco Irmãs": MPM, Alcântara Machado, Norton, SallesInteramericana e a Denison Propaganda.

23 Revista Propaganda, no 145 , junho 1968, p.24.

${ }^{24}$ Mauro Salles. Discurso pronunciado em nome da Associação Brasileira de Propaganda, em homenagem ao dia Pan-americano de Propaganda. Revista Propaganda, no 140, janeiro de 1968, p. 24.
} 
A questão é: por que tais campanhas foram realizadas de forma esparsa, ou seja, sem um plano nacional de comunicação? A pesquisa de Fico (1996) revelou a execução de apenas uma parte do projeto original de criação do Sistema Nacional de Informações (SNI), ou seja, este apenas recolhia informações, ao invés de produzi-las.

Essa característica estaria atrelada à personalidade de Humberto de Alencar Castelo Branco, avesso a qualquer tipo de propaganda política. A reticência de Castelo criou um vácuo na comunicação entre a ditadura e a sociedade civil até o staff presidencial entender a importância da criação de um órgão responsável pela "imagem do governo", culminando na criação da Assessoria Especial de Relações Públicas, em janeiro de 1968.

Ainda que a criação da agência tenha sido anterior a algumas campanhas veiculadas, é importante frisar também que seu trabalho inicial teve caráter mais informativo e um formato típico dos órgãos oficiais de propaganda. A criação e implantação de um projeto de comunicação também foi objeto de disputa entre as facções da ditadura militar. Portanto, seu período de maior sucesso ocorreu paralelo aos anos do "milagre econômico brasileiro". A atuação da AERP nessa segunda fase teve um impacto econômico substantivo nas agências de capital nacional, como o caso da gaúcha MPM Propaganda, que assumiu o topo do ranking nacional de agências por um longo período (1974 a 1991).

O surto econômico dos anos 1970 parecia ser a "recompensa" para os anos "de trabalho". Nesse novo contexto, as agências passaram a conviver com um novo anunciante, a ditadura militar. Contudo, as diretrizes da "agência oficial", ao menos por parte de algumas agências, já estavam em prática, ou pelo menos já davam sinais de existência. Isso significa dizer que algumas foram ampliadas - como o uso constante da ideia do "País que vai pra frente" e outras formas de nacionalismo -, enquanto outras como a utilização de mensagens que veiculassem o "amor" ou que exaltassem a "família" - foram paulatinamente incorporadas no discurso das agências. 


\section{Referências bibliográficas}

ALVES, Maria Helena. Estado e oposição no Brasil (1964 - 1984), Bauru: Edusc, 2005.

ARENDT, Hannah. Entre o passado e o futuro. São Paulo: Perspectiva, 2016.

ARRUDA, Maria Arminda do Nascimento. A embalagem do sistema: A publicidade no capitalismo brasileiro. Bauru: Edusc, 2004.

ASSIS, Denise de. Propaganda e cinema a serviço do golpe (1962-1964). Rio de Janeiro: Mauad, FAPERJ, 2001.

CADENA, Nelson. Brasil - 100 anos de Propaganda. São Paulo: Edições Referência, 2001.

CHOMSKY, Noam. Controle da mídia: os espetaculares feitos da propaganda. Rio de Janeiro: Graphia, 2003.

DREIFUSS, René Armand. 1964: a conquista do Estado: ação política, poder e golpe de classe. 7 ed. Rio de Janeiro: Vozes, 2008.

FICO, Carlos. Como eles agiam: os subterrâneos da ditadura militar: espionagem e polícia política. Rio de Janeiro: Ed. Record, 2001.

Reinventando o otimismo: ditadura, propaganda e imaginário social no Brasil (1969 1977). Tese de doutoramento. Programa de Pós-Graduação em História Social. Universidade de São Paulo (USP), 1996.

MAGALHÃES, Marion Brepohl. A lógica da suspeição: sobre os aparelhos repressivos à época da ditadura militar no Brasil. Rev. Brasileira de História. Vol. 17, n. 34. São Paulo, 1997.

NAPOLITANO, Marcos. "Vencer Satã só com orações": políticas culturais e cultura de oposição no Brasil dos anos 1970. In: Rollemberg, Denise e Quadradt, Samantha (org). A construção social dos regimes autoritários: Brasil e América Latina. Vol. II. Rio de Janeiro: Civilização Brasileira, 2010. PP. 145 - 176.

REZENDE, Maria José. A ditadura militar no Brasil: Repressão e pretensão de legitimidade 1964 1984. Londrina: Ed. Uel, 2001.

ROLLEMBERG, Denise e QUADRAT, Samantha Viz. A construção social dos regimes autoritários: Europa, volume 1. Rio de Janeiro: Civilização Brasileira, 2010.

SILVA, Juremir Machado. 1964. Golpe midiático-civil-militar. Porto Alegre: Sulina, 2014. 